\title{
Uma experiência de uso do georreferenciamento e do mapeamento no processo de territorialização na Atenção Primária à Saúde
}

\author{
An experience of georeferencing and mapping use in the process of \\ territorialization in Primary Health Care
}

Melina Alves de Camargos', Fátima Corrêa Oliver ${ }^{2}$

DOI: 10.1590/0103-1104201912321

RESUMO Este artigo tem como objetivo relatar a experiência do uso de ferramentas que instrumentalizam o processo de territorialização na Atenção Primária à Saúde. Como recursos metodológicos para nortear a inserção e apreensão das situações problema foram utilizados a observação participante e o diário de campo. A inserção junto ao Núcleo Ampliado de Saúde da Família e Atenção Básica propiciou a apreensão das problemáticas, e, com isso, optou-se por desenvolver mapeamento e georreferenciamento a fim de colaborar com o processo de territorialização da unidade, visibilização de serviços e populações. O processo de territorialização, que está para além de incumbências burocráticas, demonstrou ser um desafio para os profissionais. Foi possível construir ferramentas junto às equipes da Unidade Básica de Saúde em questão, que pode ser norte para outras equipes e equipamentos de saúde.

PALAVRAS-CHAVE Saúde pública. Atenção Primária à Saúde. Mapeamento geográfico. Integralidade em saúde.

\begin{abstract}
This article aims to report the experience of using tools that instrumentalize the process of territorialization in Primary Health Care. As methodological resources to guide the insertion and apprehension of problem situations, participant observation and field diary were used. The insertion with Family Health and Primary Care Extended Centers (Nasf-AB) provided the apprehension of the problems, and, with this, it was decided to develop mapping and georeferencing in order to collaborate with the process of territorialization of the unit, visibility of services and populations. The process of territorialization, which goes beyond bureaucratic incidents, has proved to be a challenge for professionals. It was possible to build tools with the Basic Health Unity teams in question, that could be north to other teams and health equipment.
\end{abstract}

KEYWORDS Public health. Primary Health Care. Geographic mapping. Integrality in health.

\footnotetext{
1 Hospital Israelita Albert Einstein - São Paulo (SP), Brasil. melinacamargos.to@gmail.

com

2 Universidade de São Paulo (USP) - São Paulo (SP), Brasil.
} 


\section{Introdução}

\section{Atenção primária, rede e território}

A Política Nacional de Atenção Básica (PNAB), lançada em 2006, caracteriza a Atenção Primária à Saúde (APS) como um

conjunto de ações de saúde, no âmbito individual e coletivo, que abrangem a promoção e a proteção da saúde, a prevenção de agravos, o diagnóstico, o tratamento, a reabilitação e a manutenção da saúde ${ }^{\mathbf{1 ( 1 0 )} \text {. }}$

Entre seus objetivos, ressaltam-se a gestão democrática e participativa; o trabalho em equipe com base em tecnologias de alta complexidade, porém, de baixa densidade tecnológica; as respostas às necessidades advindas do território; e a concepção de sujeitos singulares e complexos que estão imersos em um dado contexto sócio-histórico-cultural'1.

Em 2012, com a segunda edição da PNAB, o Ministério da Saúde (MS) reforça os objetivos já destacados, contudo, introduz novos conceitos em relação ao papel da APS, considerando-a ordenadora da Rede de Atenção à Saúde (RAS)2. Já a PNAB de 2017 reafirma o papel de ordenadora da RAS e considera que é preciso reconhecer as necessidades de saúde da população adstrita para oferta de assistência adequada $^{3}$. No Brasil, para o alcance de uma APS forte e resolutiva, adota-se como arranjo organizacional principal a Estratégia Saúde da Família (ESF).

O processo de territorialização na APS pode ser entendido como uma técnica de planejamento e gestão que objetiva propor intervenções a partir da realidade 4 . Para isto, a PNAB de 2012 estabelece, enquanto atribuição comum a todos os profissionais, a participação no processo de territorialização para atuar na identificação de grupos, famílias e indivíduos expostos a riscos e vulnerabilidades ${ }^{2}$. No entanto, Mafra e Chaves ${ }^{5}$ chamam a atenção para a condução deste processo, que facilmente é reduzido e simplificado, tornando-se apenas um procedimento burocrático.

Faria ${ }^{4}$ ressalta a importância da reflexão acerca do território da saúde versus o território dos sujeitos. Ele faz esta consideração devido à demarcação do território anteceder o entendimento da vida dos grupos sociais. Compreende-se que há uma delimitação prática, baseada na oferta de serviços, que pode ser entendida também como um processo de dominação e apropriação.

A apropriação denota algo de fora, que se projeta e se impõe. Obviamente, a apropriação requer um agente apropriador (o serviço), uma relação de poder (a oferta, o recurso) e uma área a ser apropriada (o território)4(136).

Feita a crítica, chama a atenção o fato de o processo de territorialização ser inacabado. Este processo incessante pode trazer à tona outro tipo de apropriação, ligada ao modo de vida das pessoas e à percepção das necessidades, invertendo a lógica de subjugação do território ao serviço.

Com isso, propõe-se, aqui, a concepção da territorialização como um processo que extrapola limites geográficos e incumbências burocráticas, e se aproxima de um trabalho que permite o entendimento da vida e das necessidades, o que necessariamente requer ações não assumidas apenas pela APS. A partir do entendimento do território como ponto de partida, é preciso voltar-se para ele, na tentativa de entendê-lo. Desta forma, os produtos de tal processo assumem um diálogo com as premissas da APS e com as dificuldades já apresentadas.

Assim, o objetivo deste artigo é relatar a experiência do uso de ferramentas que instrumentalizam o processo de territorialização na APS.

\section{O território em questão}

A Unidade Básica de Saúde (UBS) localiza-se na região Oeste do município de São Paulo (SP) e está sob a administração de uma Organização Social de Saúde (OSS). É responsável por 
24.800 habitantes, cuja assistência está distribuída entre sete Equipes de Saúde da Família (EqSF) com apoio do Núcleo Ampliado de Saúde da Família e Atenção Básica (Nasf-AB). É importante assinalar que se trata de território não contíguo, composto por uma área sede (onde se localiza a UBS) e duas áreas descontínuas. As chegadas da sétima EqSF e do Nasf-AB são recentes, sendo que a mudança de equipe multiprofissional para Nasf-AB foi iniciada em março de 2018. Anteriormente, a UBS caracterizava-se como mista e contava com uma equipe multiprofissional.

A UBS passou, em setembro de 2017, por uma mudança de gerência, assim como todas as outras UBS da região Oeste sob a administração da atual OSS. Historicamente, é polo de recepção de alunos de graduação da área da saúde, de diferentes programas de residência multiprofissional e residência médica.

Essa UBS foi também parte do processo formativo de uma participante do programa de residência multiprofissional em saúde coletiva e atenção primária da Faculdade de Medicina da Universidade de São Paulo (USP), sendo tal experiência parte do processo de construção de seu conhecimento teórico-prático, que será mais amplamente abordado abaixo.

\section{Métodos}

O período inicial foi planejado para que a residente mencionada se inserisse nas atividades, nos compromissos e nas ações desenvolvidas pela equipe do Nasf-AB. Como recursos metodológicos para nortear essa inserção, foram utilizados a Observação Participante (OP) e o Diário de Campo (DC).

Optou-se por inserção via equipe do Nasf-AB devido ao seu caráter multiprofissional, à sua capacidade de tecer relações com os trabalhadores e por sua circulação na UBS/ território, tendo em vista sua finalidade. $\mathrm{O}$ núcleo possui, como objetivos, apoiar técnica e pedagogicamente o trabalho das EqSF, contribuir com a ampliação do escopo de ações da APS, otimizar a resolutividade dos casos atendidos, reduzir encaminhamentos desnecessários e contribuir para a efetivação da integralidade do cuidado ${ }^{6-8}$.

O uso da OP justifica-se com base na exigência de inserção no grupo analisado, não apenas como observador, mas como parte dele, sendo necessário interagir, partilhar o cotidiano e buscar a compreensão dos significados de cada situação, $0^{9,10}$. Segundo Queiroz ${ }^{9}$, com a OP é possível realizar análises da realidade social e "captar os conflitos e tensões existentes para identificar grupos sociais que têm em si a sensibilidade e motivação para as mudanças necessárias"9(278).

Já os registros dos aspectos descritivos e reflexivos do cotidiano foram efetuados em DC com o intuito de identificar situações que emergiram no cotidiano do trabalho. Lima"1 afirma a importância do uso do DC, pois refere que reler repetidamente as reflexões oferece ferramentas de planejamento para as intervenções e indica caminhos para busca de sustentação teórica.

A imersão compreendeu o envolvimento nas seguintes atividades: consultas compartilhadas e individuais; fórum conjunto de reabilitação e saúde mental; grupo gerencial avançado; visitas domiciliares; grupos da UBS; aproximações territoriais; reuniões gerais, do Nasf-AB, de conselho gestor, de apoio matricial e com escolas de ensino infantil e fundamental. Isto sem falar na participação em discussões sobre o processo de trabalho do Nasf-AB e em aproximações com o banco de dados de pessoas com limitações para a participação nas atividades do cotidiano, que, em suma, contemplam Pessoas com Deficiência (PcD) e em sofrimento mental. Destaca-se que a participação nessas atividades foi pactuada com gerência e trabalhadores.

A vivência desse período propiciou a aproximação da realidade do serviço e da prática dos profissionais. Com isso, foi possível, além de identificar problemas do cotidiano, vivenciá-los e experimentá-los 
inteiramente, sendo que o envolvimento na rotina e a constituição de relações interpessoais apresentaram a riqueza e a complexidade do campo.

Durante e após o processo de imersão, as trocas com os profissionais foram fundamentais para delimitar o caminho a seguir. Nesse processo, realizou-se, de forma compartilhada ao Nasf-AB, a identificação dos eixos de situações-problema, sendo eles: processo de trabalho em saúde; território, territorialização e intersetorialidade; e gestão da clínica.

Os eixos foram idealizados de forma a agrupar situações que surgiram e eram frequentemente identificadas como problemáticas. A partir dessa identificação, foi necessário avaliar, junto à equipe, que contribuições seriam mais pertinentes ao momento, considerando o tempo de permanência da residente. A opção pelo uso do georreferenciamento e do mapeamento respondem ao incômodo expresso pela atual equipe, de não conhecer o território, não ter feito parte do processo de territorialização construído até então, como também não conhecer a rede de saúde e nem mesmo as características da população adstrita.

Esse processo também contou com o envolvimento das EqSF e, como estratégia, utilizou-se de reuniões semanais ao longo de quatro meses para a concepção da problemática, a criação de espaço de diálogo, interação e compreensão do momento vivenciado e produtos gerados com a UBS.

Vale ressaltar que os produtos foram disponibilizados via e-mail e memorando da unidade para todas as equipes, em documento fechado. Foi acordado que, para a equipe do Nasf-AB, seriam disponibilizados os documentos com permissão para edição junto a um tutorial instrutivo.

Assim, como ponto de partida, optou-se por iniciar a atualização do banco de dados sobre pessoas com limitações para a participação nas atividades do cotidiano existente na UBS, que constitui parte do mapeamento das demandas e necessidades dos moradores do território.

\section{Ferramentas construídas para apoiar o processo de territorialização}

O mapeamento e o georreferenciamento são ferramentas que objetivam tornar o processo de territorialização algo contínuo, favorecendo a aproximação entre profissionais e população. Assim, espera-se uma melhor compreensão das necessidades de saúde, bem como o planejamento do processo de trabalho, a incorporação de populações que não são consideradas como prioritárias, e o trabalho em rede e no território.

\section{O mapeamento como instrumento de visibilização de populações}

O mapeamento iniciou-se em 2003, a partir da iniciativa da terapeuta ocupacional da unidade, em parceria com o Laboratório de Reabilitação com Ênfase no Território, do curso de Terapia Ocupacional da USP, com base nos dados dos cadastros das famílias coletados via Agentes Comunitários de Saúde (ACS), busca ativa, contato com lideranças comunitárias e informantes-chave ${ }^{\mathbf{1 2}}$.

Sua execução veio do questionamento e da delimitação do lugar da equipe multiprofissional na APS. Outro fator foi/é a crítica à ESF como modelo que visa à superação do paradigma biomédico, porém, devido às tensões cotidianas e aos arranjos assistenciais/gerenciais que hegemonizam a prática pautada na queixa-conduta, ainda direciona suas ações com base em procedimentos que assumem como norte a compreensão biomédica da saúde ${ }^{12,13}$.

De acordo com Pinto ${ }^{\mathbf{1 3}}$, a ESF pauta-se em ações programáticas, atendimentos a grupos prioritários, atividades domiciliares e articulação com a comunidade. A redução de alguns desses preceitos pode levar ao enquadramento das pessoas nos agravos que lhes competem, de acordo com determinada programação ou prioridade, deixando de fora parte da população. Outro fator de crítica é o direcionamento insistente dos esforços às demandas 
emergentes, o que anula o planejamento, que tem como base as necessidades do território.

No Brasil, desde a década de 1970, discute-se a necessidade de ampliar a oferta de serviços descentralizados. Neste sentido, não se anula a oferta de serviços especializados, porém, é repensado o modelo pautado nesta oferta devido à sua cobertura limitada. Também é deste período a proposição da Reabilitação Baseada na Comunidade (RBC), pela Organização Mundial da Saúde (OMS), que tem o intuito de ampliar a cobertura assistencial por meio da mobilização comunitária e do estímulo a PcD e seus familiares, para participarem de atividades comunitárias, com o objetivo de promover a visibilidade social e a legitimação desse segmento ${ }^{\mathbf{1 4}}$.

Em diálogo com essa proposição, Oliver ${ }^{15}$ apresenta o desenvolvimento de um programa que tem como base o território e suas possibilidades de colaborar com processos inclusivos.

Isso significa não somente que se desenvolve em território geograficamente delimitado, mas que o próprio território é a principal estratégia de compreensão da problemática da deficiência e de intervenção sobre ela15.

Assim como a RBC propõe um trabalho de base territorial, o Movimento da Luta Antimanicomial, junto à Reabilitação Psicossocial, instituem o acolhimento e o tratamento de pessoas em sofrimento mental em serviços de base territorial, tornado, assim, a APS parte da rede de cuidados ofertados a essa população ${ }^{16}$.

Nesse sentido, entende-se o território como um espaço vivo, construído por relações sociais, econômicas e políticas. Como também, um conjunto de objetos e ações em constante processo de interação, que expressa em si as condições de vida, saúde e acesso a serviços, sendo um elemento que colabora na compreensão e caracterização da população ${ }^{17,18}$.

A atualização do mapeamento objetivou contribuir para o processo de territorialização e na superação desse modelo pautado nas demandas emergentes e em grupos prioritários. Centrar-se no planejamento com base nas necessidades abre possibilidades de provocar mudanças e/ou incorporação das potências desse modelo assistencial e de visibilizar pessoas que enfrentem processos de estigma, de incompreensão das necessidades enquanto grupo social e de exclusão, que envolvem também a barreira do acesso ${ }^{19}$.

\section{O georreferenciamento como ins- trumento de visibilização de ações e serviços}

$\mathrm{O}$ georreferenciamento caracteriza-se como um processo pelo qual informações textuais descritivas de uma localidade são traduzidas em representações gráficas, tornando possível relacionar dados de um determinado contexto a um posicionamento geográfico, o que permite a visualização e a busca por informações de interesse de forma rápida e simplificada ${ }^{20}$.

Objetivou disponibilizar informações geográficas e descritivas de serviços de referência de uso da população. Para isso, utilizou-se o software livre Google Maps, com a inserção de 109 ações e serviços de modo manual e a criação de dez camadas temáticas, que podem ser utilizadas individualmente ou sobrepostas. Além disso, acoplado a essa ferramenta, criou-se um documento guia, que contém informações específicas sobre cada equipamento.

Após a confecção de parte do georreferenciamento e do documento guia, os resultados parciais foram apresentados em reuniões do Nasf-AB e das EqSF com a finalidade de propiciar a apreciação do produto, com espaço para sugestões. As reuniões foram escolhidas por serem momentos em que toda a equipe esteve presente, em especial, os ACS, por viverem no território e serem elos entre os usuários e os serviços de saúde.

Selecionar a camada e o serviço gera dados sobre a localidade, além de uma breve descrição. Assim, se o profissional quiser obter mais informações sobre determinado serviço, ele poderá clicar em um link que o direcionará a um outro documento guia, contendo informações mais 
completas. São elas: objetivo, atividades desenvolvidas, a quem encaminhar, como encaminhar, período de atendimento, endereço e contato. Optou-se por realizar um documento em paralelo com o intuito de facilitar a busca de informações sem a poluição do georreferenciamento, o que poderia dificultar o uso da ferramenta.

A figura 1 apresenta a atual visualização do georreferenciamento com a sobreposição de camadas.

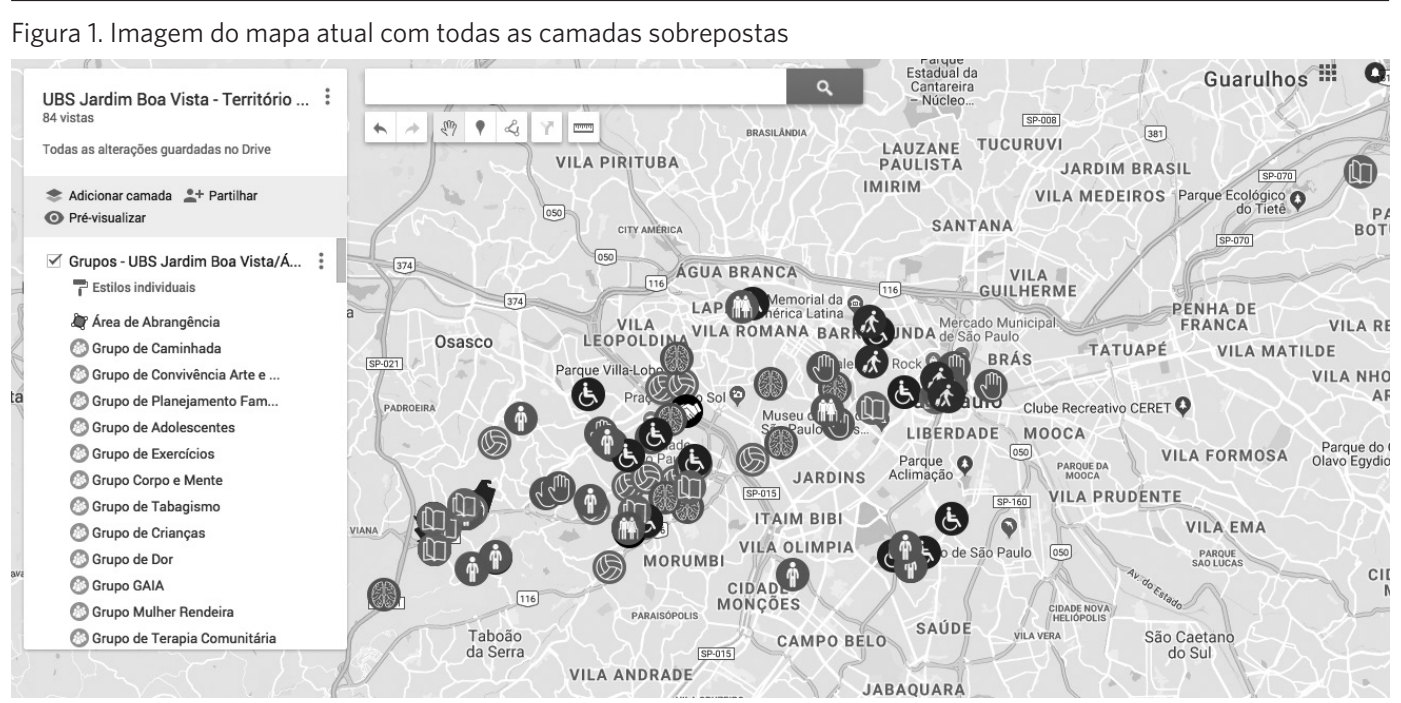

\section{Resultados}

Em relação à atualização do mapeamento, é possível visualizar um retrato atual de cada
EqSF e da UBS. A tabela 1 fornece informações em número absoluto sobre faixa etária, sexo e condições de saúde prevalentes.

Tabela 1. Mapeamento de pessoas com limitações para participação em atividades do cotidiano em número absoluto por Equipe de Saúde da Família, sexo, faixa etária e condições de saúde prevalentes

\begin{tabular}{|c|c|c|c|c|c|c|c|c|}
\hline \multirow[t]{2}{*}{ Variáveis } & \multicolumn{8}{|c|}{ Equipes de Estratégia Saúde da Família } \\
\hline & 01 & 02 & 03 & 04 & 05 & 06 & 07 & Total \\
\hline \multicolumn{9}{|l|}{ Sexo } \\
\hline Masculino & 16 & 31 & 37 & 47 & 18 & 31 & 06 & 186 \\
\hline Feminino & 13 & 30 & 25 & 45 & 19 & 29 & 03 & 164 \\
\hline \multicolumn{9}{|l|}{ Faixa etária } \\
\hline Criança & 02 & 07 & 11 & 08 & 04 & 07 & 03 & 42 \\
\hline Adolescente & 02 & 04 & 07 & 07 & 06 & 09 & 02 & 37 \\
\hline Jovem & 03 & 06 & 06 & 19 & 07 & 09 & - & 50 \\
\hline Adulto & 10 & 26 & 31 & 28 & 13 & 21 & 04 & 133 \\
\hline Idoso & 12 & 15 & 07 & 30 & 07 & 14 & - & 85 \\
\hline
\end{tabular}


Tabela 1. (cont.)

\begin{tabular}{|c|c|c|c|c|c|c|c|c|}
\hline \multirow[t]{2}{*}{ Variáveis } & \multicolumn{8}{|c|}{ Equipes de Estratégia Saúde da Família } \\
\hline & 01 & 02 & 03 & 04 & 05 & 06 & 07 & Total \\
\hline \multicolumn{9}{|c|}{ Condições de saúde prevalente } \\
\hline Deficiência intelectual & 06 & 08 & - & 23 & 07 & 10 & - & 54 \\
\hline Deficiência física & 06 & - & 11 & 22 & 13 & 12 & - & 64 \\
\hline Sofrimento mental & 05 & 23 & - & - & 05 & - & 04 & 37 \\
\hline Deficiência múltipla & - & 08 & 12 & - & - & - & - & 20 \\
\hline $\mathrm{ADNPM}^{*}$ & - & - & 11 & - & - & - & - & 11 \\
\hline$A \bigvee C^{\star \star}$ & - & - & - & 14 & - & 10 & - & 24 \\
\hline $\mathrm{DOM}^{\star \star \star}$ & - & - & - & - & - & - & 03 & 03 \\
\hline Dor & - & - & - & - & - & - & 01 & 01 \\
\hline Outras $s^{\star \star \star \star}$ & 12 & 22 & 28 & 33 & 12 & 28 & 01 & 136 \\
\hline
\end{tabular}

Como panorama geral da unidade, em relação ao sexo, revela-se maior número de homens mapeados. Quanto à faixa etária, a de maior concentração foi a de adultos, seguida por idosos e jovens. E no que se refere às condições de saúde prevalentes, a categoria outras contempla maior número, seguida por deficiência física e intelectual.

Na variável condições de saúde prevalentes, optou-se por elencar as três condições que concentraram maior número absoluto por equipe. Com isto, mesmo que na tabela a EqSF esteja sem um número citado em alguma das condições, é possível que existam pessoas que se enquadrem em algum dos padrões adotados.

Em relação ao georreferenciamento, o quadro 1 expõe os dados sobre as camadas, número de serviços e localização.

Quadro 1. Descrição do georreferenciamento por camada, número de serviços e localização

\begin{tabular}{lll}
\hline Camadas & $\begin{array}{l}\text { Número total de } \\
\text { açães e serviços }\end{array}$ & $\begin{array}{l}\text { Localização por região de São Paulo } \\
\text { (SP) e demais cidades do estado }\end{array}$ \\
\hline Grupos UBS & 13 & Oeste \\
Esporte, Lazer e Cultura & 15 & Oeste/Osasco \\
Rede Socioassistencial & 07 & Oeste/Centro \\
Rede de Atenção Psicossocial & 10 & Oeste/Centro/Cotia \\
Rede de Atenção à Pessoa em Situação de Violência & 09 & Oeste/Centro \\
Rede de Atenção à Pessoa com Deficiência & 18 & Oeste/Centro/Sul \\
Inclusão e Qualificação Profissional & 13 & Oeste/Sul/Sudoeste/Osasco/Centro \\
Cursinhos Populares/Contraturno/Inclusão Escolar & 10 & Oeste/Centro/Leste \\
Rede de Atenção à Pessoa Idosa & 08 & Oeste/Centro \\
Serviço de Atendimento ao Imigrante & 05 & Oeste/Centro \\
\hline
\end{tabular}

Fonte: Elaboração própria. 
Em todas as camadas existem serviços localizados na região Oeste, o que pode ser um facilitador para o uso da comunidade. No entanto, algumas das camadas estão distribuídas entre cinco e três regiões. Este fato, aliado às dificuldades de acesso que algumas populações enfrentam, pode influenciar a capacidade de efetivação do cuidado ${ }^{19}$.

As figuras 2 e 3 representam os eixos com maior e menor número de serviços georreferenciados e a classificação dos serviços por categoria.

Figura 2. Eixos com maior presença de serviços
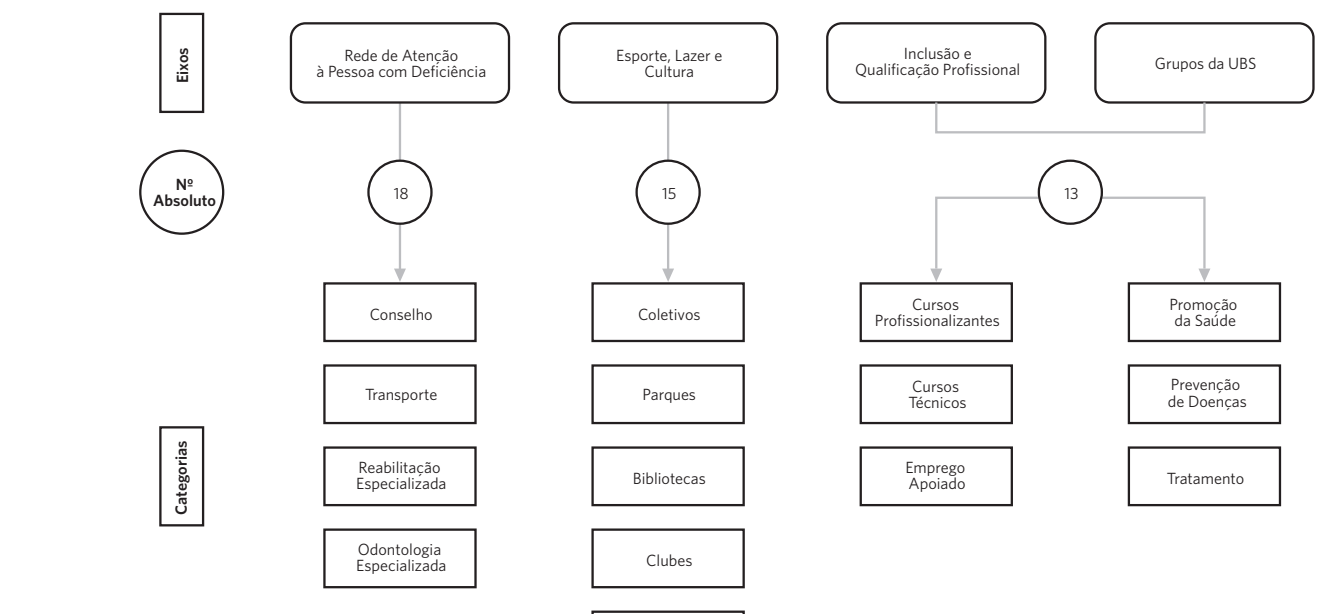

Centros Culturais

Fonte: Elaboração própria.

Figura 3. Eixos com menor presença de serviços
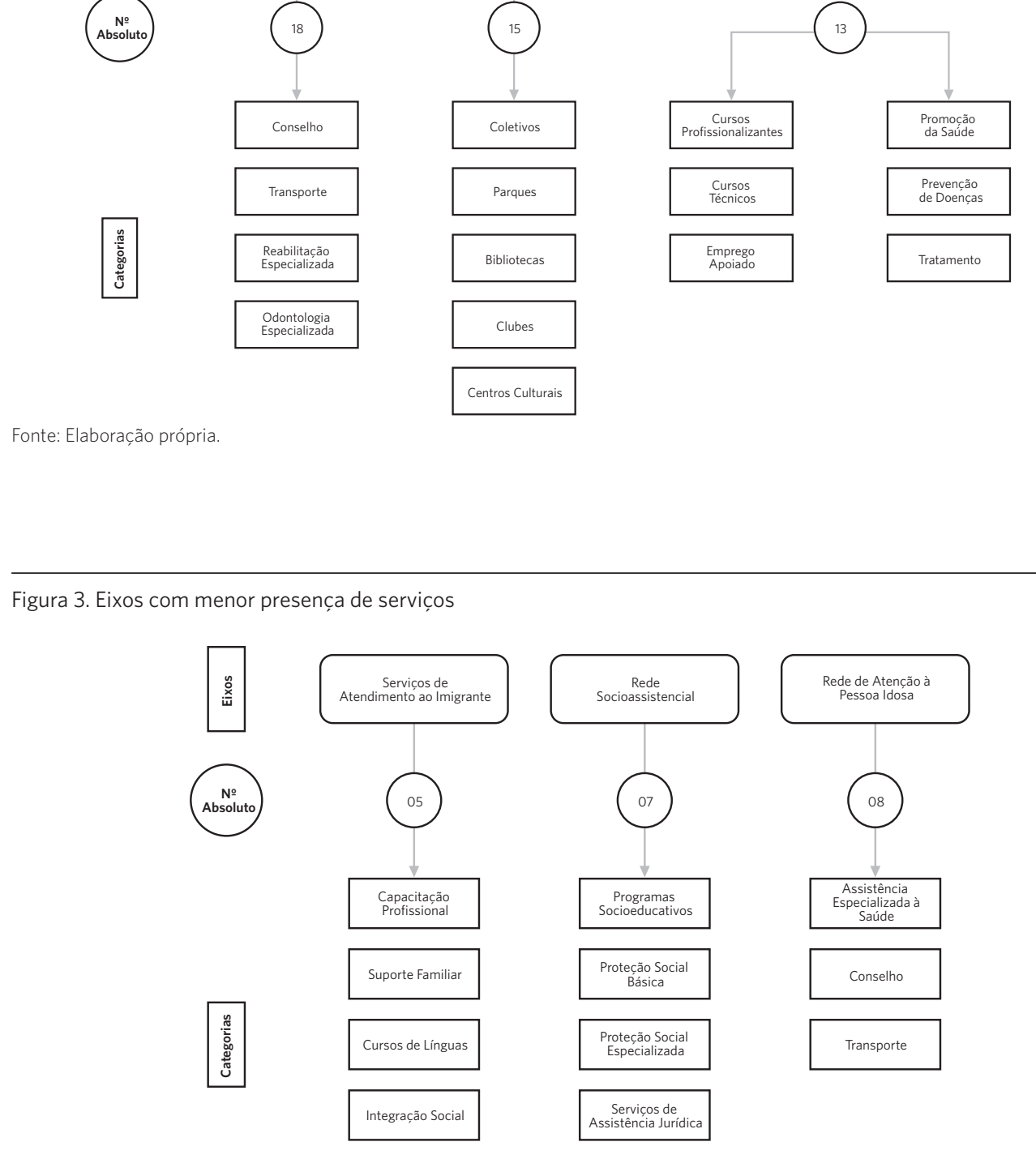

Serviços de Assistênćia Jurídica 
Relaciona-se a incorporação de maior número de serviços no eixo 'Rede de Atenção à Pessoa com Deficiência' na intencionalidade de atrelar o mapeamento à oferta de serviços direcionados às PcD. O eixo de 'Inclusão e Qualificação Profissional' também abarca serviços voltados para o atendimento a PcD. Outro ponto foi o maior interesse dos profissionais do Nasf-AB por esses serviços, dada as demandas apreendidas pelos mesmos e a tentativa de ofertar respostas. Esta mobilização pode se relacionar à cultura de encaminhamentos, demonstrando, assim, falta de clareza e iniciativas de ações de reabilitação no âmbito da APS.

No segundo eixo, 'Esporte, Lazer e Cultura', a busca realizada por proximidade revelou que a região é favorecida pela presença desses equipamentos. No entanto, se faz necessário ressaltar que apenas três dos equipamentos estão na área de abrangência da UBS, o que pode ser um dificultador de acesso.

O terceiro eixo é o de 'Grupos' que são oferecidos pela UBS. Em geral, os grupos são realizados exclusivamente pela equipe do Nasf-AB, com exceção de três: 1) com participação de uma enfermeira da ESF; 2) realizado por EqSF no território; 3) conduzido por ACS na UBS. Apenas dois dos grupos conduzidos pelo Nasf-AB são realizados no território e de forma intersetorial. Os demais grupos são realizados na UBS e abrangem as temáticas: promoção da saúde, prevenção de doenças e tratamento para questões relativas à saúde mental, dor e desenvolvimento infantil.

\section{Discussão}

Propõe-se uma leitura de sobreposição dos produtos. Ao visibilizar populações, são apresentadas estratégias de trabalho, possíveis parcerias e propostas de desenvolvimento de trabalho intersetorial que envolvam saúde, educação, justiça, ação social e cultura. Tudo isto, considerando concepção ampliada de saúde, com vistas à afirmação e à validação do direito dessas populações.
As apresentações para as equipes tiveram retorno positivo. Os profissionais revelaram uma prática que se limitava a procedimentos e se mantiveram no próprio consultório. Neste sentido, é possível considerar os produtos como auxílio e provocação para mudanças, ainda que tímidas, da prática assistencial.

A inserção de ações/serviços no georreferenciamento iniciou-se por equipamentos do Sistema Único de Saúde (SUS) e, em seguida, foram incorporadas as que possuíam atuação no território da UBS. Optou-se por essa realização dada a dificuldade dos profissionais de vislumbrarem o que havia disponível na rede já com pactuações pré-estabelecidas.

Já as camadas foram criadas em diálogo com as necessidades expressas, e para a incorporação de dados foram consideradas informações partilhadas por trabalhadores da rede, obtidas por meio de visitas, ligações telefônicas, consultas em guias e informações em páginas da web. Consideraram-se serviços que extrapolavam a rede de saúde instituída formalmente, incorporando serviços do Sistema Único de Assistência Social (Suas); da Secretaria de Esporte, Lazer e Juventude; da Secretaria Municipal do Verde e Meio Ambiente; da Secretaria da Educação; de movimentos sociais; da Secretaria Municipal de Mobilidade e Transportes; de ações do terceiro setor; de universidades públicas e particulares; e ações desenvolvidas pelos moradores do território.

\section{Considerações finais}

Os produtos propiciaram a visita dos profissionais em locais de interesse, o que foi fundamental para o início do processo de territorialização, de trabalhos de base territorial e/ou intersetorial, objetivando o cuidado compartilhado, produzindo parcerias em ações ainda durante o período de execução deste trabalho.

Houve boa receptividade por parte dos profissionais, e perspectivas de uso. Houve, ainda, relatos de que o processo de territorialização se apresentava como um gargalo, e 
*Orcid (Open Researcher and Contributor ID). que produtos como esse poderiam subsidiar $\mathrm{o}$ início do processo de superação. O Nasf-AB não apenas recebeu os resultados, mas foi parceiro no percurso de construção e se deixou afetar pelas possibilidades de um processo de territorialização, o que se mostra como desafio constante.

Entende-se que o tempo atuou como um dos limitadores principais, pois o processo de apreensão do problema, junto ao planejamento e à execução dos produtos, compreende parâmetros que extrapolam o tempo cronológico, mas exigem inserção qualificada. Outro fator dialoga com o gargalo apresentado, sendo ele o cumprimento de certos padrões assistenciais/gerenciais que atuam como elementos hegemonizadores das práticas, deixando pouco diálogo com ações contra-hegemônicas. Destaca-se que a leitura aqui realizada é apenas uma das possíveis, sendo esta escolhida porque disponibiliza uma experiência de territorialização que pode ser útil em outros pontos da rede.

Como continuidade, indica-se mais do que o seguimento do processo de territorialização pautado na atualização dos produtos. Estes podem indicar caminhos ou pontos de partida de uma prática subjugada ao território. No entanto, outras formas de uso podem otimizar o trabalho das equipes, como, por exemplo, a incorporação da distribuição espacial de populações acompanhadas, a proporção de pessoas por faixa etária, a visualização de cada microárea a partir do grau de vulnerabilidade, a incorporação de ações que acontecem no pulsar da vida no território e a qualificação dos serviços a partir do acesso dos usuários.

Pretende-se, com a visibilização de serviços e disponibilização de meios para acesso, facilitar o trabalho territorial e em rede. É possível dizer que esse foi apenas o início do georreferenciamento que pode ser feito na UBS. O propósito não foi o de apresentar um trabalho acabado ou sem margens para alterações e sim, de ser o início de um dos modos possíveis de compor o processo de territorialização.

\section{Colaboradores}

Camargos MA (0000-0002-7899-8451*) e Oliver FC (0000-0002-7288-8921*) contribuíram igualmente na elaboração do manuscrito.

\section{Referências}

1. Brasil. Ministério da Saúde. Política Nacional de Atenção Básica. Brasília, DF: MS; 2006.

2. Brasil. Ministério da Saúde. Política Nacional de Atenção Básica. Brasília, DF: MS; 2012.

3. Brasil. Ministério da Saúde. Portaria no 2.436, de 21 de setembro de 2017. Aprova a Política Nacional de
Atenção Básica, estabelecendo a revisão de diretrizes para a organização da Atenção Básica, no âmbito do Sistema Único de Saúde (SUS). Diário Oficial da União. 24 Set 2017.

4. Faria RM. A Territorialização da atenção primária à saúde no Sistema Único de Saúde e a construção de uma perspectiva de adequação dos serviços aos per- 
fis do território. Hygeia. 2013; 6(16):131-147.

5. Chaves MMN, Mafra MRP. O Processo de Territorialização e a Atenção à Saúde no Programa Saúde da Família. Família, Saúde e Desenvolvimento (UFPR), 2004; 6(2):127-133.

6. Brasil. Ministério da Saúde. Portaria n ${ }^{0} 154$, de Janeiro de 2008. Cria os Núcleos de Apoio à Saúde da Família. Diário Oficial da Únião. 24 Jan 2008.

7. Gonçalves RMA, Lancman S, Sznelwar LI, et al. Estudo do trabalho em Núcleos de Apoio à Saúde da Família (NASF), São Paulo, Brasil. Rev. bras. saúde ocup. 2015; 40(131): 59-74.

8. Klein AP, d'Oliveira AFPL. O "cabo de força" da assistência: concepção e prática de psicólogos sobre o Apoio Matricial no Núcleo de Apoio à Saúde da Família. Cad. Saúde Pública. 2017; 33(1).

9. Queiroz DT, Vall J, Souza AMA, et al. Observação participante na pesquisa qualitativa: conceitos e aplicações na área da saúde. R Enferm UERJ. 2007; 15(2):276-283.

10. Santos SR. Métodos qualitativos e quantitativos na pesquisa biomédica. J Pediatr. 1999; 75(6):401-406

11. Lima TCS, Mioto RCT, Prá KRD. A documentação o cotidiano da intervenção dos assistentes sociais: algumas considerações acerca do diário de campo. Revista Textos \& Contextos. 2007; 6(1):93-104.

12. Nicolau SM, Aoki M, Oliver FC. A atenção às pessoas com deficiências no território: uma experiência da Terapia Ocupacional no Programa de Saúde da Família em um bairro periférico da cidade de São Paulo. Revista de Terapia Ocupacional da Bahiana, 2007; 20(3):5-10.

13. Oliver FC, Aoki M, Nicolau SM, et al. Reabilitação com Ênfase no Território: atenção a pessoas com deficiência e formação de terapeutas ocupacionais. In:
Silva S, Digiampietri L, organizadores. (Re) Conhecendo a USP - contribuições do ensino, da pesquisa e da extensão no campo das deficiências. São Paulo: FEUSP, 2017. p. 121-131.

14. Oliver FC, Tissi MC, Castro LH. Reabilitação baseada na Comunidade - produzindo ações no contexto sociocultural. Quaestio (UNISO), Sorocaba - SP. 2000; 2(1):75-84.

15. Leão A, Barros S. Território e serviço comunitário de saúde mental: as concepções presentes nos discursos dos atores do processo da Reforma Psiquiátrica Brasileira. Saúde e Sociedade. 2012; 21(3):572-586

16. Gondim GMM, Monken M, Rojas LI, et al. O Território da Saúde: a organização do sistema de saúde e a territorialização. In: Miranda AC, Barcellos C, Moreira JC, et al., organizadores. Território, Ambiente e Saúde. Rio de Janeiro: Fiocruz. 2008. p. 1-22.

17. Santos MA. Natureza do Espaço: Técnica e tempo. Razão e Emoção. São Paulo: Hucitec. 1996.

18. Silva RAS, Silva ACC, Oliver FC. In: Cavalcante Neto JL, Silva OON. Diversidade e movimento: diálogos possíveis e necessários. Curitiba: CRV. 2016. p. 183204.

19. Silveira IH, Oliveira BFA, Junger WL. Utilização do Google Maps para o georreferenciamento de dados do Sistema de Informações sobre Mortalidade no município do Rio de Janeiro, 2010-2012. Epidemiologia e Serviços de Saúde. 2017; 26(4):881-886.

20. Oliver FC, Aoki M, Nicolau SM. Pessoas com deficiências e participação na vida social: a emergência de um campo de atenção em saúde. In: $8^{\circ} \mathrm{CBSC}$ e $11^{\circ}$ CMSP, RJ, 2006.

Recebido em 27/03/2019

Aprovado em 04/09/2019

Conflito de interesses: inexistente

Suporte financeiro: não houve 